J. Lake Sci. (湖泊科学) , 2018, 30(2): 431-440

DOI 10. 18307/2018. 0214

(c) 2018 by Journal of Lake Sciences

\title{
巢湖浮游藻类功能群的组成特性及其影响因素”
}

\author{
王徐林 ${ }^{1}$, 张 民 ${ }^{2 * *}$, 殷 进 ${ }^{1,2 * *}$ \\ (1:扬州大学环境学院, 扬州 225000) \\ (2: 中国科学院南京地理与湖泊研究所湖泊与环境国家重点实验室, 南京 210008)
}

\begin{abstract}
摘 要: 2015 年 1-12 月逐月采集了巢湖 9 个断面的浮游植物, 并对所采植物进行功能群划分, 结果显示, 巢湖的浮游植 物可以划分为 15 个功能群: C、N、P、MP、S2、X1、X3、Y、F、J、H1、H2、LM、M、W1. 不同时期调查的植物优势功能群存在差 异, 其中 $\mathrm{H} 2$ 在 12 次调查中的优势度均 $\geqslant 0.02$, 成为巢湖的绝对优势功能群, $\mathrm{H} 2$ 功能群的组成藻类为鱼腥藻, 次要的功能 群为 $\mathrm{M}$, 主要组成㩰类为微囊藻, 两个功能群均为富营养化功能类群. 巢湖植物优势功能群不同时期的演替规律为: 1 月 $\mathrm{H} 2+\mathrm{Y}$ 经 2 月 $\mathrm{H} 2+\mathrm{J}, 3$ 月 $\mathrm{H} 2,4$ 月 $\mathrm{H} 2+\mathrm{F}, 5$ 月 $\mathrm{H} 2,6$ 月 $\mathrm{M}, 7$ 月 $\mathrm{M}+\mathrm{H} 2,8$ 、 9 月 $\mathrm{M}, 11$ 月 $\mathrm{H} 2+\mathrm{M}$ 转变为 12 月 $\mathrm{H} 2 . \mathrm{RDA}$ 分析结 果显示, 巢湖植物功能群分布受水环境因子影响较为明显, 整体上, 水温、溶解性总磷、溶解性总氮、高锰酸盐指数和水深 是影响巢湖植物功能群分布格局的主要因素.
\end{abstract}

关键词: 巢湖; 㩰类功能群;优势度;环境因子

\section{Composition and influential factors of phytoplankton function groups in Lake Chaohu}

\author{
WANG Xulin ${ }^{1}$, ZHANG Min ${ }^{2 * *} \&$ YIN Jin ${ }^{1,2 * *}$ \\ (1: College of Environmental Sciences, Yangzhou University, Yangzhou 225000, P.R.China) \\ (2: State Key Laboratory of Lake Science and Environment, Nanjing Institute of Geography and Limnology, Chinese Academy \\ of Sciences, Nanjing 210008, P.R. China)
}

Abstract: This study was performed at the whole year in 2015 at 9 sampling sections of Lake Chaohu, aiming to analyze the temporal and spatial variation of the phytoplankton function groups. A total of 15 kinds of phytoplankton function groups were identified: C, N, P, MP, S2, X1, X3, Y, F, J, H1, H2, LM, M, W1. The phytoplankton function groups was dominated by H2 based on the dominant degree $(\geqslant 0.02)$ and significant differences were found on phytoplankton function groups across 9 sampling sections in the twelve investigations, which mainly consisted of Anabaena, the second was M, which was mainly composed of Microcystis. Particularly, these two communities were characterized by the eutrophication. The successional routine of dominant phytoplankton function groups in different months could be summarized as follow: $\mathrm{H} 2+\mathrm{Y}$ in January, to $\mathrm{H} 2+\mathrm{J}$ in February, to $\mathrm{H} 2$ in March, to $\mathrm{H} 2+\mathrm{F}$ in April, to $\mathrm{H} 2$ in May, to M in June, to $\mathrm{M}+\mathrm{H} 2$ in July, to M in August and September, to H2+M in November, to H2 in December. RDA was used to explore the relationship between phytoplankton function groups and major environmental factors. The results showed that temperature, total soluble phosphorus, total nitrogen solubility, permanganate index and water depth were the most important factors influencing the temporal and spatial distribution of phytoplankton function groups.

Keywords: Lake Chaohu; phytoplankton function groups; dominant degree; environmental factors

作为淡水水体的主要初级生产者, 浮游植物在水生生态系统中有着至关重要的作用 ${ }^{[1]}$. 根据生态位原 理,生态学家们把生活习性和生存策略相似的浮游植物种类归于同一个 “功能群” ${ }^{[2]}$, 作为群落结构与响应 分析的基本单元. 浮游植物功能群是近年来的研究热点, 已被广泛应用于浮游植物生态学研究 ${ }^{[3-4]}$, 目前, 应 用较多的功能群划分系统有 FG (Functional Groups)、MFG (Morphology-Functional Groups)、MBFG

* 国家自然科学基金项目 (31470520) 资助. 2017-02-20 收稿;2017-05-22 收修改稿. 王徐林( 1993 ), 男, 硕士研 究生; E-mail: 1982326135@qq.com.

** 通信作者; E-mail: mzhang@ niglas.ac.cn; yinjin@yzu.edu.cn. 
(Morphology-Based Functional Groups) 和 PFT(Plant Functional Types) ${ }^{[5]}$. FG 是最早提出的功能群系统, 该功 能群分类方法的建立具有最重要的两个生态学假设: 其一, 适应能力强的物种比适应能力弱的物种更能耐 受环境中的限制因素; 其二, 包含多种环境因子的复杂环境总会被一系列适应性相似的物种占据. FG (Functional Groups) 法的提出具有划时代的意义, 该方法能反映藻类的栖息地属性、对环境的耐受能力以及水体的 营养等级等各个方面 ${ }^{[6-7]}$, 近年来也成为我国湖泊研究者们使用最为广泛的方法 ${ }^{[8-10]}$.

巢湖 ( $\left.30^{\circ} 25^{\prime} 28^{\prime \prime} \sim 31^{\circ} 43^{\prime} 28^{\prime \prime} \mathrm{N}, 117^{\circ} 16^{\prime} 54^{\prime \prime} \sim 117^{\circ} 51^{\prime} 46^{\prime \prime} \mathrm{E}\right)$ 是我国第五大淡水湖, 位于安徽省中部, 水域面 积约 $787.4 \mathrm{~km}^{2}$, 平均水深 $3 \mathrm{~m}$, 属于长江下游左游水系. 人湖河流共 33 条, 其中巢湖水源主要来自西南部的 杭埠河一丰乐河水系, 而派河水系从西面注人巢湖, 南淝河一店埠河水系和柘臬河水系从北面注人巢湖, 白 石山河水系从南面注人巢湖, 巢湖唯一的出水口为位于东部的裕溪河, 巢湖水经此河进人长江. 巢湖是沿湖 居民重要的引用水源地, 兼具渔业生产、航运、旅游等功能. 1970s 巢湖水体处于严重的富营养化状态, 多次 出现蓝藻水华,2004 年以后全湖已达到劣 V 类水质, 水质恶化趋势十分严峻, 主要污染指标为总磷和总氮. 巢湖氮、磷污染物主要来自西北部的十五里河、南汁河等人湖河流, 导致西部湖区的氮、磷营养盐的浓度要 显著高于东部湖区 ${ }^{[11-12]}$. 浮游植物的组成也随着不同营养盐浓度呈现不同的空间分布模式和演替规 律 ${ }^{[13-14]}$, 为了进一步区分分类相近植物对生境响应的差异, 从而提升水环境管理的精确性, 本研究采用 FG 法对巢湖浮游植物功能群的时空特征进行分析, 并通过几余分析 (RDA) 明确影响浮游植物功能群演替的主 要环境因子,以期为巢湖的生态与水质监管提供理论依据和技术支撑.

\section{1 材料与方法}

\section{1 采样位点设置与采样方法}

本研究共设置 9 个采样断面 $\left(1^{\#} \sim 9^{\#}\right.$ ，图 1), 监测时间为 2015 年 $1-12$ 月.

浮游植物样品的采集使用采水器 (Uwitec, 奥地利) 采集表层、中层和底层混合样品 $500 \mathrm{ml}$, 用 $5 \%$ 的鲁 哥氏剂固定保存. 水温 ( WT) 、电导率 ( EC) 、溶解氧 ( DO) 以及 $\mathrm{pH}$ 用 YSI 多参数水质检测仪现场测定; 采用 赛氏盘对透明度 (SD) 进行测定; 采用 Speedtech SM-5A 手持式测定深仪测定水深. 取混合水样直接分装于 $200 \mathrm{ml}$ 塑料瓶中, 用于测定总氮 $(\mathrm{TN})$ 、总磷 $(\mathrm{TP})$ 、化学需氧量 $\left(\mathrm{COD}_{\mathrm{Mn}}\right)$ 、铵态氮 $\left(\mathrm{NH}_{4}^{+}-\mathrm{N}\right)$ 等环境因子.

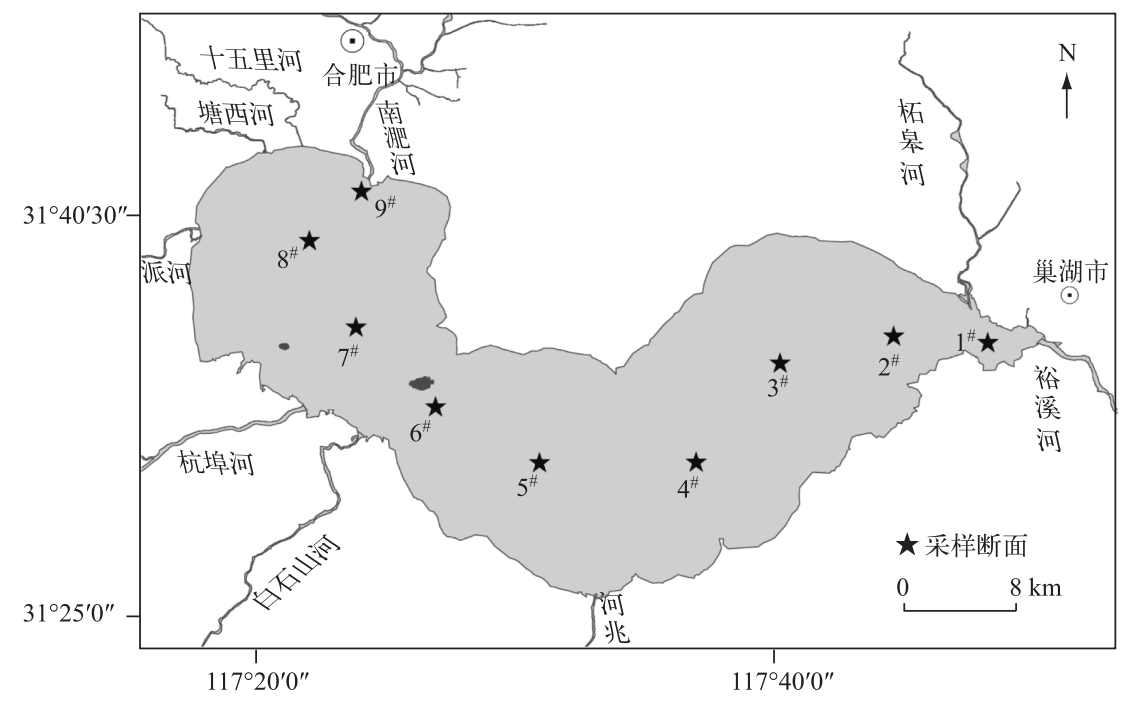

图 1 巢湖采样断面示意

Fig.1 Sampling sections of Lake Chaohu

\section{2 水环境因子的测定方法}

水体 $\mathrm{COD}_{\mathrm{Mn}} 、 \mathrm{TN} 、 \mathrm{TP}$ 、溶解态有机碳 $(\mathrm{DOC}) 、 \mathrm{NH}_{4}^{+}-\mathrm{N}$ 、硝态氮 $\left(\mathrm{NO}_{3}^{-}-\mathrm{N}\right)$ 、亚硝态氮 $\left(\mathrm{NO}_{2}^{-}-\mathrm{N}\right)$ 、磷酸盐 $\left(\mathrm{PO}_{4}^{3-}-\mathrm{P}\right)$ 、 
溶解性总磷 (DTP)、溶解性无机碳 (DIC) 的测定方法参照《水和废水监测分析方法》 ${ }^{[15]}$. 其中, 采用高镇酸盐 法测法测定 $\mathrm{COD}_{\mathrm{Mn}}$; 钿酸铵分光光度法测定 TP 和 DTP 浓度; 碱性过硫酸钾一紫外分光光度法测定 TN 和 DTN 浓度; 纳氏试剂比色法测定 $\mathrm{NH}_{4}^{+}-\mathrm{N}$ 浓度; 紫外分光光度法测定 $\mathrm{NO}_{3}^{-}-\mathrm{N}$ 浓度; 重氮耦合分光光度法测定 $\mathrm{NO}_{2}^{-}-\mathrm{N}$ 浓度; 钼锑抗分光光度法测定 $\mathrm{PO}_{4}^{3-}-\mathrm{P}$ 浓度.

\section{3 数据分析}

1.3.1 浮游植物功能群生物量计算 浮游植物样品静置 $24 \mathrm{~h}$ 后吸去上清液, 最后根据藻细胞数浓缩至 10 $30 \mathrm{ml}$, 取混匀样品 $0.1 \mathrm{ml}$, 在光学显微镜下鉴定计数, 每个样品计数 2 片取其平均值. 生物量则根据藻类的 平均体积与密度乘积计算, 其中藻类平均体积根据目微尺实测藻体大小, 根据藻类的形状, 使用相应的体积 公式进行计算, 藻类密度按 1 进行计算. 浮游植物功能群生物量指的是功能群的代表性藻种 (属) 的生物量 之和, 通过各代表性藻种 (属) 的生物量相加得出. 比如巢湖植物功能群 P 的代表性藻种 (属) 包括新月藻和 脆杆藻, 那么该功能群生物量则为新月藻和脆杆藻的生物量之和 ${ }^{[16]}$.

1.3.2 浮游植物功能群优势度分析 优势度 $(y)$ 根据浮游植物功能群的出现频率及相对生物量来确定 ${ }^{[17]}$, 即 $y=f_{i} \cdot P_{i}$, 式中, $f_{i}$ 为第 $i$ 功能群的出现频率, $P_{i}$ 为第 $i$ 功能群生物量占总植物生物量的比例, 当 $y \geqslant 0.02$ 时, 定 义为优势功能群 ${ }^{[18]}$.

1.3.3 年余分析 (RDA) 采用 Canoco for Windows 5 软件对物种数据进行除趋势对应分析 (DCA), 每个排序 轴的梯度长度分别是 $2.43 、 1.92 、 1.79 、 2.02$ 均小于 3 , 故对功能群数据和环境数据进行 RDA 分析. 浮游植物 功能群矩阵经过 $\lg (x+0.0001)$ 转换, 环境因子数据除 $\mathrm{pH}$ 外全部进行 $\lg (x+1)$ 转换. 利用前向选择法对环境 因子进行篮选, 最终结果仅显示有显著贡献的环境因子. RDA 分析结果用功能群一环境因子关系的双序图 表示, 图中环境因子用带有箭头的线段表示, 向量长短表示其在主轴中的作用,线段所处象限代表环境因子 与排序轴间的正负关系. 分析时, 作出某一功能群与环境因子连线的垂直线, 垂直线与环境因子连线相交点 离箭头越近, 表示该种与该类生境因子的正相关性越大, 处于另一端的则表示与该类环境因子具有的负相 关性越大.

\section{2 结果}

\section{1 浮游植物生物量变化及功能群划分}

从不同月份浮游藻类的分布来看 (图 2), 巢湖 1 月藻类生物量变化范围为 $1.417 \sim 15.338 \mathrm{mg} / \mathrm{L}$, 最大值 出现在 $1^{\#}$ 点, 而 $5^{\#}$ 点生物量最小; 2 月藻类生物量变化范围为 $0.629 \sim 4.170 \mathrm{mg} / \mathrm{L} ; 3$ 月藻类生物量变化范围 为 $0.387 \sim 2.974 \mathrm{mg} / \mathrm{L} ; 4$ 月藻类生物量变化范围为 $0.407 \sim 3.635 \mathrm{mg} / \mathrm{L}$, 最大值出现在 $2^{\#}$ 点, 而 $8^{\#}$ 点的生物量 最小, 整体来看, 浮游藻类生物量从大到小依次为东巢湖 $>$ 西巢湖 $>$ 中巢湖; 5 月藻类生物量变化范围为 $0.897 \sim 6.625 \mathrm{mg} / \mathrm{L} ; 6$ 月藻类生物量变化范围为 $0.296 \sim 3.784 \mathrm{mg} / \mathrm{L} ; 7$ 月藻类生物量变化范围为 $0.570 \sim 5.846$ $\mathrm{mg} / \mathrm{L}$, 整体来看, 浮游藻类生物量从大到小依次为中巢湖 $>$ 西巢湖 $>$ 东巢湖 $; 8$ 月藻类生物量变化范围为 $0.505 \sim 3.309 \mathrm{mg} / \mathrm{L}$, 浮游藻类生物量从大到小依次为东巢湖 $>$ 中巢湖 $>$ 西巢湖; 9 月藻类生物量变化范围为 $0.620 \sim 3.852 \mathrm{mg} / \mathrm{L} ; 10$ 月藻类生物量变化范围为 $0.158 \sim 6.130 \mathrm{mg} / \mathrm{L} ; 11$ 月藻类生物量变化范围为 $1.697 \sim$ $9.326 \mathrm{mg} / \mathrm{L}$, 最大值出现在 $4^{\#}$ 点, 而 $3^{*}$ 点的生物量最小, 整体来看, 浮游藻类生物量从大到小依次为中巢湖 $>$ 西巢湖>东巢湖; 12 月藻类生物量变化范围为 $0.805 ~ 9.649 \mathrm{mg} / \mathrm{L}$.

根据 Reynold 等 ${ }^{[19-20]}$ 提出的功能群分类法, 对所检出的浮游植物进行功能分类, 将具备相同或类似生态 属性的浮游植物归在一个功能群内, 巢湖的浮游植物可以分为 15 个功能群: C、N、P、MP、S2、X1、X3、Y、F、 $\mathrm{J} 、 \mathrm{H} 1 、 \mathrm{H} 2 、 \mathrm{LM} 、 \mathrm{M} 、 \mathrm{~W} 1$ (表 1).

\section{2 浮游植物优势功能群及其分布特征}

如果某个功能群的优势度 $\geqslant 0.02$, 则达到优势地位, 称之为优势功能群. 从不同时期浮游植物功能群的 优势度来看, $1 、 3$ 月浮游藻类的优势功能群为 $C 、 M P 、 Y 、 H 2,2$ 月为 $C 、 P 、 M P 、 Y 、 J 、 H 2,4$ 月为 $P 、 M P 、 F 、 J 、 H 2$, 5 月为 $H 2 、 M, 6$ 月为 $J 、 H 2 、 M, 7$ 月为 $C 、 M P 、 Y 、 H 2 、 L M 、 M, 8$ 月为 $Y 、 H 2 、 L M 、 M, 9 、 10$ 月均为 $H 2 、 L M 、 M, 11$ 、 12 月均为 $\mathrm{H} 2$. 其中, $\mathrm{H} 2$ 在 12 次的调查中的优势度均 $\geqslant 0.02$, 成为巢湖的绝对优势功能群. 本研究中浮游藻 类功能群的时空分布特征及其影响因子分析均在上述优势功能群中展开. 

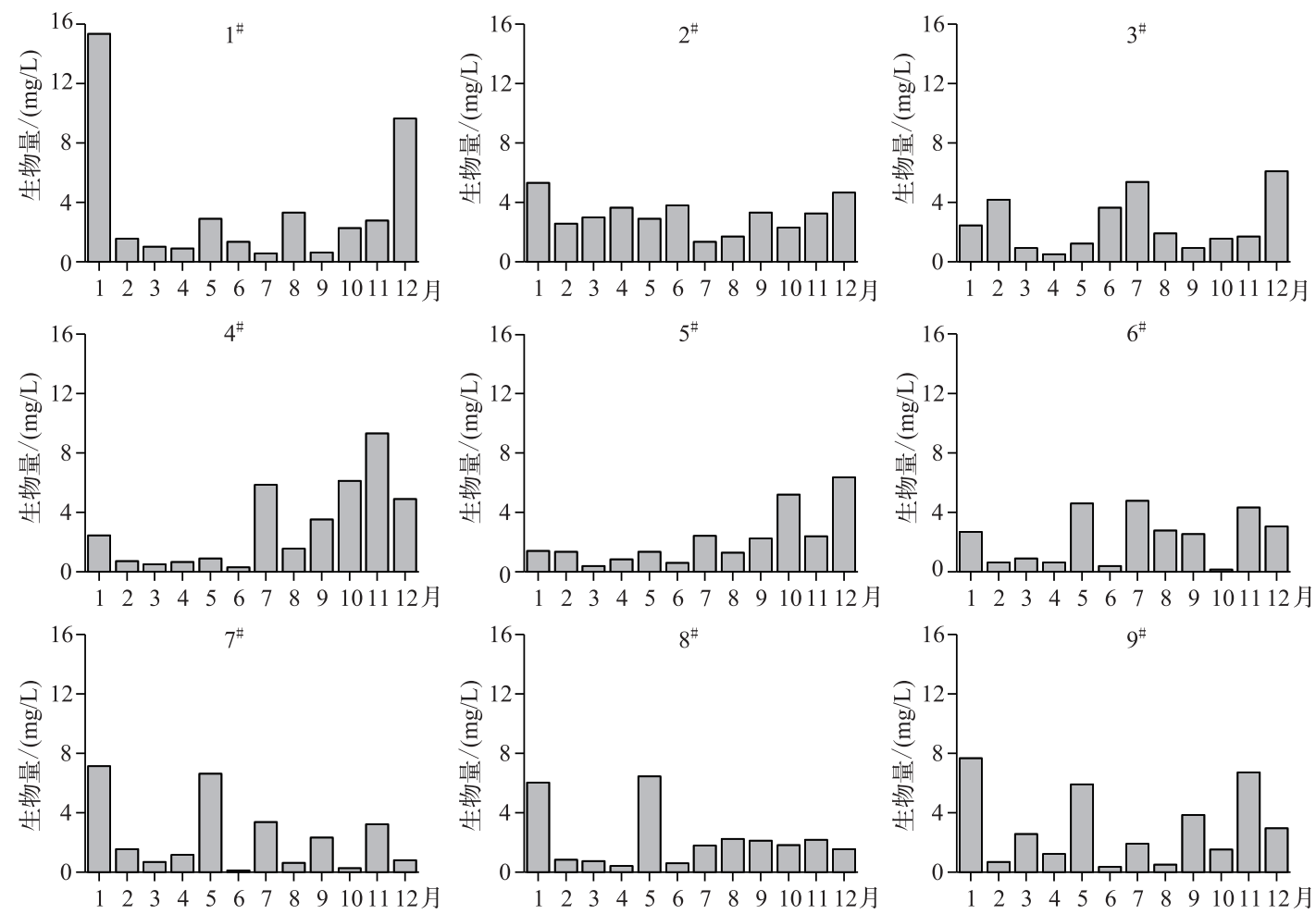

图 22015 年巢湖浮游植物生物量的时空变化

Fig.2 Temporal and spatial variation of phytoplankton of Lake Chaohu in 2015

表 1 巢湖浮游植物功能群划分 ${ }^{[5]}$

Tab.1 Phytoplankton function groups division in Lake Chaohu ${ }^{[5]}$

\begin{tabular}{|c|c|c|}
\hline \multicolumn{2}{|c|}{ 功能群 代表性种 (属) } & \multirow{2}{*}{$\begin{array}{l}\text { 功能群生境特征 } \\
\text { 富营养、中小型水体 }\end{array}$} \\
\hline $\mathrm{C}$ & 小环藻 Cyclotella sp. & \\
\hline $\mathrm{N}$ & 鼓藻 Cosmarium sp. & 中营养型混合层水体 \\
\hline $\mathrm{P}$ & 新月藻 Closterium sp.、脆杆藻 Fragilaria sp. & 混合程度较高的中富营养浅水水体 \\
\hline MP & $\begin{array}{l}\text { 颗粒直链硅藻 Aulacoseira granulate、异极藻 Gomphonema sp. 舟形藻 } \\
\text { Navicula } \mathrm{sp} \text { 、颤 藻 Oscillatoria } \mathrm{sp} \text {. 、双菱 藻 Surirella } \mathrm{sp} \text {. 丝藻 } \\
\text { Ulothrix sp. }\end{array}$ & 频繁扰动的浑浊型浅水湖泊 \\
\hline S2 & 螺旋藻 Spirulina sp. & 温暖、高碱性、浅水水体 \\
\hline $\mathrm{X} 1$ & 纤维藻 Ankistrodesmus sp. & 超富营养、浅水水体 \\
\hline $\mathrm{X} 3$ & 小球藻 Chlorella sp. 、弓形藻 Schroederia sp. & 浅水、清水、混合层水体 \\
\hline $\mathrm{Y}$ & 卵形隐藻 Cryplomonas ovata & 静水水体 \\
\hline $\mathrm{F}$ & 月牙藻 Selenastrum sp.、卵囊藻 Oocystis sp. & 浅水、清水、混合层水体 \\
\hline $\mathrm{J}$ & $\begin{array}{l}\text { 盘星藻 Pediastrum sp. 空星藻 Coelastrum sp.、十字藻 Crucigenia sp.、 } \\
\text { 四角藻 Fetraedron sp.、拟新月藻 Closteriopsis sp.、栅藻 Scendesmus sp. }\end{array}$ & 混合的高富营养浅水水体 \\
\hline H1 & 束丝藻 Aphanizomenon sp. & 富营养分层水体,浅水湖泊 \\
\hline $\mathrm{H} 2$ & 鱼腥藻 Dolichospermum sp. & 富营养分层水体,浅水湖泊 \\
\hline LM & 飞燕角甲藻 Ceratium hirundinella & 富营养混合水体 \\
\hline M & 微囊藻 Microcystis sp. & 较稳定的中富营养水体, 透明度不宜太低 \\
\hline W1 & 裸藻 Euglena sp.、扁裸藻 Phacus sp. 、尖尾裸藻 Euglena gasterosteu & 富含有机质,或农业废水和生活污水的水体 \\
\hline
\end{tabular}




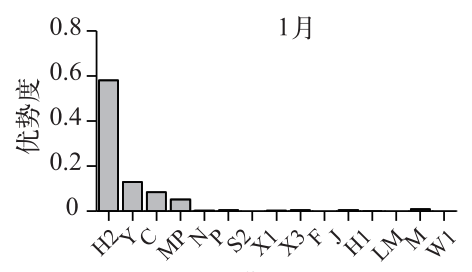

浮游藻类功能群

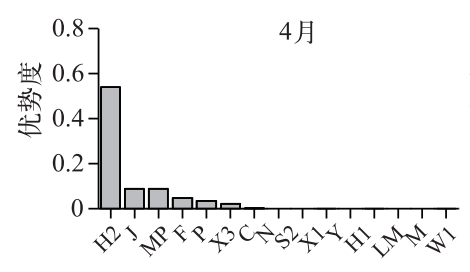

浮游藻类功能群



浮游藻类功能群

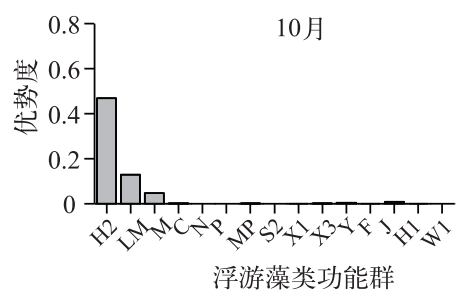



浮游藻类功能群

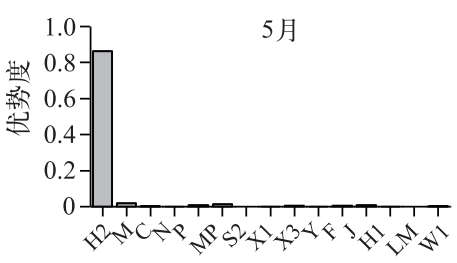

浮游藻类功能群

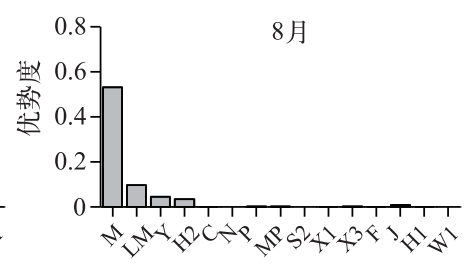

浮游藻类功能群



浮游藻类功能群

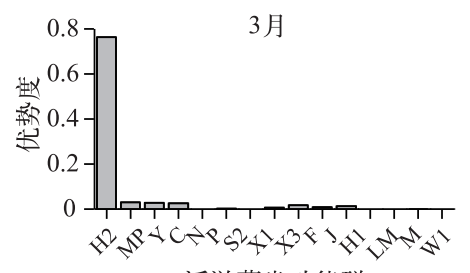

浮游藻类功能群

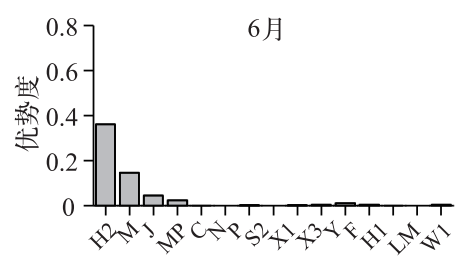

浮游藻类功能群



浮游藻类功能群

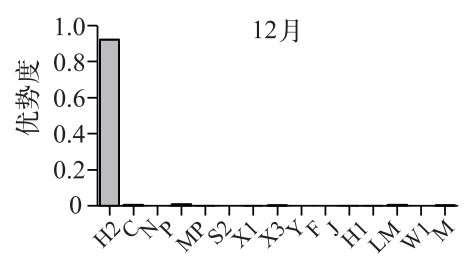

浮游藻类功能群

图 32015 年巢湖不同月份浮游藻类功能群优势度

Fig.3 Dominance of phytoplankton function groups in different months in Lake Chaohu in 2015

从不同时期浮游植物的功能群组成来看 (图 4), 1 月藻类功能群 H2、Y 在各采样断面均有分布, 其中, $\mathrm{H} 2$ 在 $1^{\#} \sim 6^{\#}$ 点处均占据绝对优势. 2 月各采样断面的主要功能群由 1 月的 $\mathrm{H} 2+\mathrm{Y}$ 转变成 $\mathrm{H} 2+\mathrm{J} .3$ 月各采样 断面的主要功能群由 2 月的 $\mathrm{H} 2+\mathrm{J}$ 转变成 $\mathrm{H} 2, \mathrm{H} 2$ 在 $1^{\#} 、 2^{\#} 、 6^{\#} 、 8^{\#} 、 9^{\#}$ 点占据绝对优势. 4 月各采样断面的主要 功能群由 3 月的 $\mathrm{H} 2$ 转变为 $\mathrm{H} 2+\mathrm{F}$, 整体来看, $\mathrm{H} 2$ 自西巢湖至东巢湖呈现逐渐下降再上升的趋势. 5 月各采 样断面的主要功能群由 4 月的 $\mathrm{H} 2+\mathrm{F}$ 转变为 $\mathrm{H} 2.6$ 月各采样断面的主要功能群由 5 月的 $\mathrm{H} 2$ 转变为 $\mathrm{M}$, 其 中, $M$ 在 $1^{\#} 、 4^{\#} 、 5^{\#}$ 点占据绝对优势, 其它点分布较少. 7 月各采样断面的主要功能群由 6 月的 $M$ 转变为 $M+$ $\mathrm{H} 2$, 其中, $M$ 在 $5^{\#} 、 6^{\#} 、 8^{\#}$ 点占据绝对优势, $\mathrm{H} 2$ 在 $3^{\#} 、 4^{\#}$ 点占据优势, 而 MP 在除 $7^{\#}$ 点外均有分布. 8 月各采样 断面的主要功能群由 7 月的 M+H2 转变为 $M$, 值得注意的是, $8^{\#}$ 点以 LM 占据优势, 而 M 所占比例较小. 9 月 各采样断面的主要功能群仍为 M. 11 月各采样断面的主要功能群由 9 月的 M 转变为 $\mathrm{H} 2+\mathrm{M}, \mathrm{H} 2$ 在全点均占 据绝对优势, 而 M 在全点分布较少. 12 月各采样断面的主要功能群由 11 月的 $\mathrm{H} 2+\mathrm{M}$ 转变为 $\mathrm{H} 2, \mathrm{H} 2$ 在所有 采样断面均占据绝对优势.

\section{3 浮游植物优势功能群与环境因子的 RDA 分析}

选取植物优势功能群与环境因子进行 RDA 分析, 利用前向选择法最终笁选出 5 个对巢湖 2015 年浮游 植物功能群有显著相关的环境因子. 第一轴解释了 $13.96 \%$ 的群落结构变化, 第二轴解释了 $7.37 \%$ 的群落结 构变化, 前两轴共解释了群落结构变化的 $21.33 \%$. 全年的分析结果显示, $\mathrm{H} 1$ 与 $\mathrm{COD}_{\mathrm{Mn}}$ 呈强正相关, 与水深及 

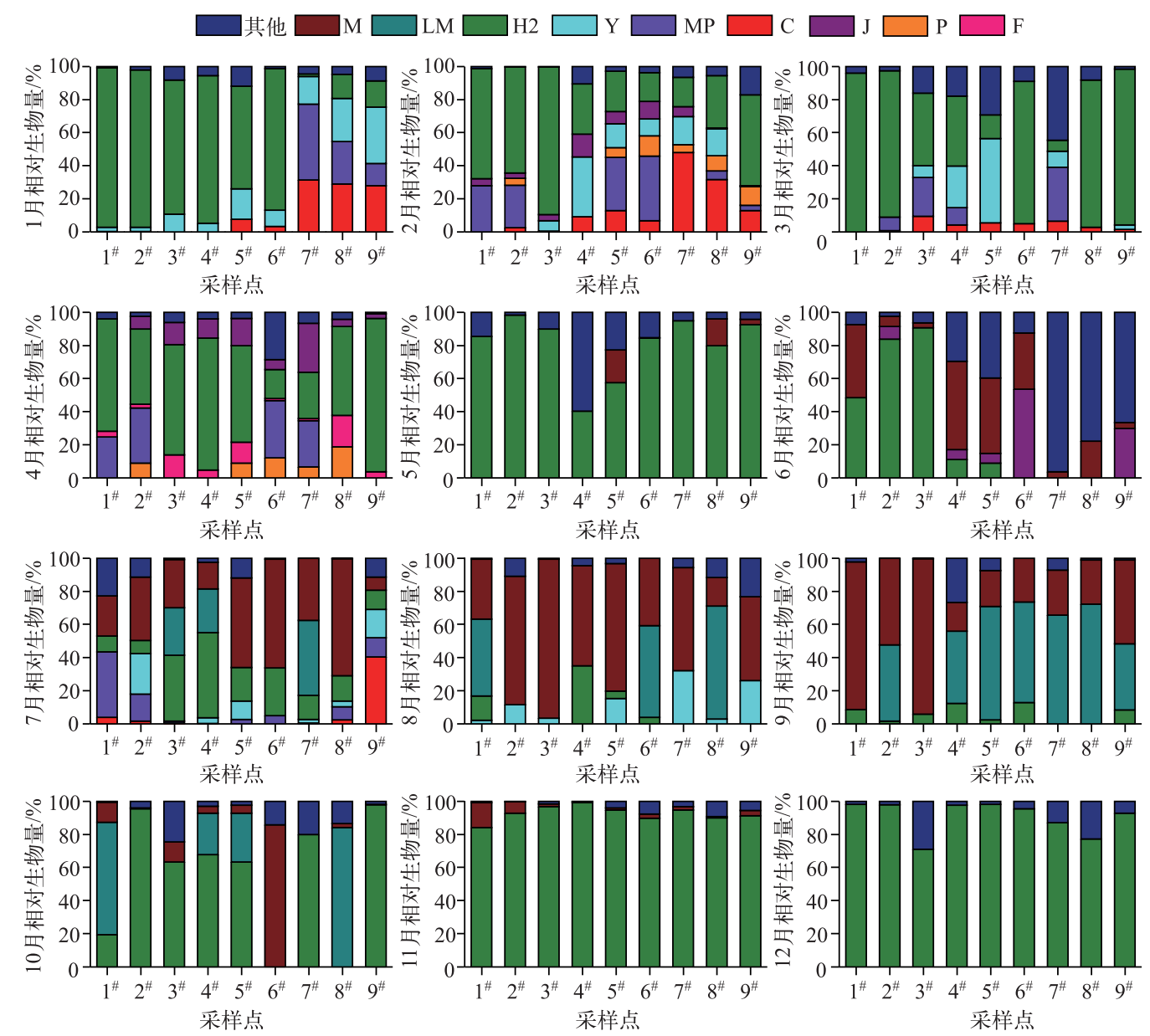

图 42015 年巢湖不同月份浮游植物功能群组成

Fig.4 Composition of phytoplankton function groups in different months in Lake Chaohu in 2015

水温均呈一定正相关, 而与其它环境因子呈负相关; $\mathrm{H} 2$ 与 $\mathrm{COD}_{\mathrm{Mn}}$ 呈一定正相关, 而与其它环境因子呈负相 关; X1 与所有环境因子均呈负相关; P 与 DTN、DTP 浓度均呈现一定正相关, 而与其它环境因子呈负相关; X3 与 DTN 浓度呈强正相关, 与 DTP 浓度呈一定正相关, 而与其它环境因子呈现负相关; F、C 均与 DTN 浓度 呈正相关, 与 DTP 浓度呈一定正相关, 而与其它环境因子呈负相关; J 与 DTN 浓度呈现强正相关, 均与 DTP 浓度、水温、水深呈一定正相关, 而与其它环境因子呈负相关; W1 与 DTP 浓度呈现强正相关, 与 DTN 浓度、 水温、水深呈一定正相关, 而与其它环境因子呈负相关; N 与 DTP 浓度呈现强正相关, 与 DTN 浓度、水温、水 深呈一定正相关, 而与其它环境因子呈负相关; $\mathrm{Y}$ 与水温、水深均呈强正相关, 与 DTP 浓度、COD $\mathrm{CD}_{\mathrm{n}}$ 呈一定正

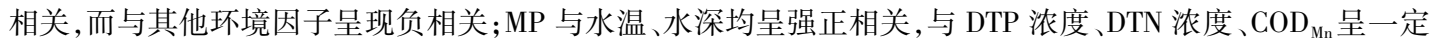
正相关; $\mathrm{LM} 、 \mathrm{M}$ 均与水温、水深、 $\mathrm{COD}_{\mathrm{Mn}}$ 呈现一定正相关, 而与其它环境因子呈现负相关. 整体来看, $\mathrm{COD}_{\mathrm{Mn}}$ 、 水深、水温、DTP 浓度和 DTN 浓度是影响全年浮游植物功能群分布的主要环境因子(图 5).

夏季的东、西湖区点位均沿着第一轴和第二轴的正方向分布,与温度呈正相关,冬季的东、西湖区点位 主要沿第二轴的负方向分布, 与水温呈负相关. 而春、秋季点位, 或者是中部湖区的点位主要分布在坐标轴 原点附近,这些点位的功能群组成相对复杂 (图 6). 


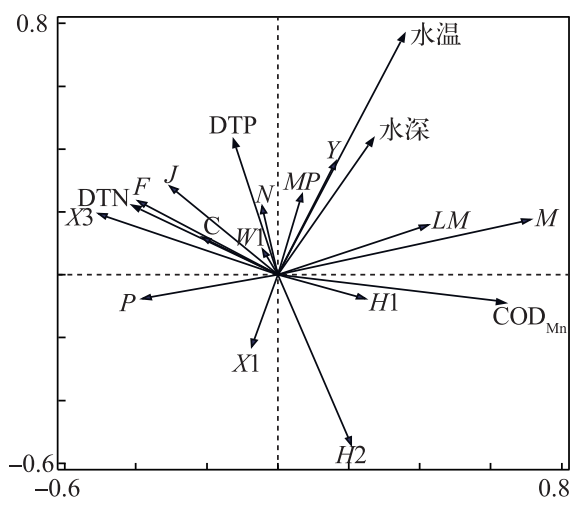

图 5 巢湖不同月份浮游植物优势功能群与主要环境因子的 RDA 分析

Fig.5 RDA analysis of phytoplankton dominant function groups and principal environment factors in different months in Lake Chaohu

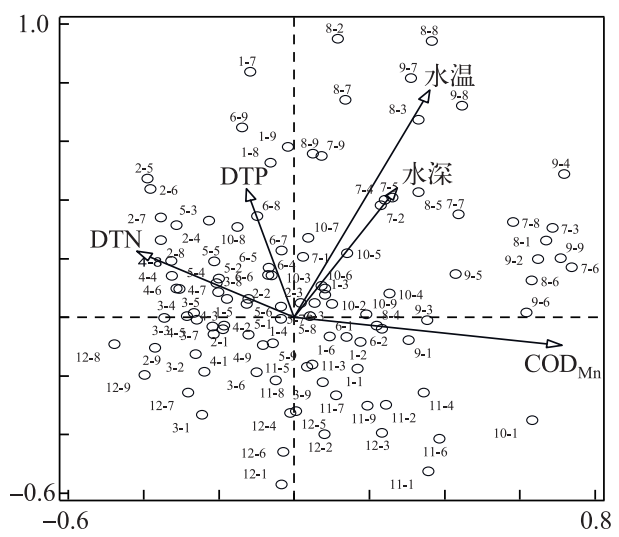

图 6 巢湖不同月份点位与主要环境因子的 RDA 分析

(其中点位号的前一个数字表示月份, 后一个数字表示点位,如 8-2, 表示 8 月 $2^{\#}$ 点位)

Fig.6 RDA analysis of different units and principal environment factors in different months in Lake Chaohu

(The first number indicates months, the second number indicates

sampling sites, such as 8-2, indicates samping site $2^{\#}$ in August)

\section{3 讨论}

\section{1 浮游植物生物量变化及功能群划分}

2010 年姜霞 ${ }^{[21]}$ 等的调查结果显示, 夏季浮游植物组成以蓝藻门占优势, 其优势种有群体的铜绿微囊藻 (Microcystis aeruginosa)、惠氏微囊藻 (M. wesenbergii) 和丝状的水华鱼腥澡 (Anabaena flos-aquae), 归属于功 能群 M 和 H2. 常见种还包括隐球藻 (Aphanocapsa sp.) 、水华束丝藻 (Aphanizomenon flos-aquae) 和光辉色球藻 (Chroococcus sp.) ,归属于 $\mathrm{H} 1$ 和 $\mathrm{K}^{[5]}$, 其中功能群 $\mathrm{K}$ 表征富营养浅水环境特征,在本次调查中未发现.

通过对巢湖不同时期浮游植物的调查显示, 浮游植物功能群存在时空差异. 从优势功能群的代表性种 类来看, $1 、 2$ 月浮游植物以蓝藻门占绝对优势, 其次是隐藻门和硅藻门; $3 、 4 、 5 、 7 、 11 、 12$ 月浮游植物均以蓝 藻门占绝对优势; 6 月浮游植物以蓝藻门占绝对优势, 其次是隐藻门、绿藻门、裸藻门; 8 月浮游植物功能群 以蓝藻门占绝对优势, 其次是甲藻门; 9 月浮游植物功能群以蓝藻门和甲藻门占绝对优势; 10 月浮游植物功 
能群以蓝藻门占绝对优势, 其次是甲藻门.

表 2 优势功能群的重要环境解释变量

Tab.2 Significant explaining environmental variables related to the functional group

\begin{tabular}{|c|c|c|c|c|c|}
\hline 优势功能群 & 变量 & $R^{2}$ & $\operatorname{Adj} R^{2} \operatorname{Cum}\left(\right.$ Cumulative adjusted $R^{2}$ ) & $F$ & $P$ \\
\hline \multirow[t]{4}{*}{$\mathrm{H} 2$} & DTP & 0.093 & 0.085 & 10.890 & 0.002 \\
\hline & $\mathrm{COD}_{\mathrm{Mn}}$ & 0.083 & 0.161 & 10.645 & 0.001 \\
\hline & $\mathrm{pH}$ & 0.071 & 0.225 & 9.744 & 0.003 \\
\hline & DO & 0.043 & 0.263 & 6.264 & 0.019 \\
\hline $\mathrm{C}$ & TDS & 0.097 & 0.088 & 11.374 & 0.005 \\
\hline \multirow[t]{2}{*}{$\mathrm{P}$} & $\mathrm{NO}_{3}^{-}-\mathrm{N}$ & 0.104 & 0.096 & 12.303 & 0.003 \\
\hline & $\mathrm{T}$ & 0.056 & 0.144 & 7.049 & 0.009 \\
\hline \multirow[t]{3}{*}{ MP } & $\mathrm{T}$ & 0.043 & 0.034 & 4.789 & 0.025 \\
\hline & $\mathrm{pH}$ & 0.040 & 0.065 & 4.527 & 0.035 \\
\hline & $\mathrm{NO}_{3}^{-}-\mathrm{N}$ & 0.060 & 0.118 & 7.253 & 0.010 \\
\hline \multirow[t]{4}{*}{ Y } & $\mathrm{TN}$ & 0.063 & 0.054 & 7.107 & 0.014 \\
\hline & $\mathrm{T}$ & 0.062 & 0.108 & 7.388 & 0.004 \\
\hline & $\mathrm{NH}_{4}^{+}-\mathrm{N}$ & 0.089 & 0.191 & 11.793 & 0.009 \\
\hline & $\mathrm{pH}$ & 0.049 & 0.234 & 6.780 & 0.013 \\
\hline \multirow[t]{2}{*}{$\mathrm{F}$} & $\mathrm{NO}_{3}^{-}-\mathrm{N}$ & 0.107 & 0.098 & 12.733 & 0.001 \\
\hline & $\mathrm{COD}_{\mathrm{Mn}}$ & 0.055 & 0.146 & 6.865 & 0.008 \\
\hline $\mathrm{J}$ & $\mathrm{COD}_{\mathrm{Mn}}$ & 0.047 & 0.038 & 5.230 & 0.028 \\
\hline \multirow[t]{3}{*}{ LM } & $\mathrm{PO}_{4}^{3-}-\mathrm{P}$ & 0.184 & 0.176 & 23.853 & 0.001 \\
\hline & $\mathrm{NO}_{2}^{-}-\mathrm{N}$ & 0.135 & 0.306 & 20.823 & 0.001 \\
\hline & $\mathrm{pH}$ & 0.061 & 0.362 & 10.254 & 0.003 \\
\hline \multirow[t]{4}{*}{ M } & $\mathrm{pH}$ & 0.484 & 0.479 & 99.473 & 0.001 \\
\hline & $\mathrm{COD}_{\mathrm{Mn}}$ & 0.081 & 0.557 & 99.641 & 0.001 \\
\hline & $\mathrm{T}$ & 0.082 & 0.637 & 24.179 & 0.001 \\
\hline & DTP & 0.060 & 0.696 & 21.088 & 0.001 \\
\hline
\end{tabular}

从功能群的生境特征来看, 绝对优势功能群 $\mathrm{H} 2$ 在水温较低的冬季在全湖分布, 而在夏季高温期间主要 分布在东部局部湖区, 而另外一种主要功能群 $\mathrm{M}$ 主要在夏季高温期出现, 并且其生物量呈现由西向东逐步 降低的趋势, 而其他主要功能群则主要在季节演替阶段出现, 或者出现时所占生物量比例不高. H2 和 M 功 能群均是富营养化水体常见的类群, 表征了巢湖的富营养化现状, 2 个主要优势类群的演替体现了其季节性 演替过程,但是 $\mathrm{H} 2$ 功能群在夏季高温期间仍有大量分布,其原因尚不明确.

\section{2 浮游植物功能群与环境因子的相关性}

环境因子是影响浮游植物群落分布的主要驱动因素, 其中温度是影响浮游植物季节性变化的重要驱动 因子, 因此本研究中温度是显著的解释变量, 特别对于最重要的两个功能群 $\mathrm{H} 2$ 和 $M$, 温度与 $M$ (主要由微囊 藻组成) 呈正相关, 而与 H2 (主要由鱼腥藻组成) 呈负相关. Robarts ${ }^{[22]} 、 O h k u b o{ }^{[23]}$ 等研究发现微囊藻与鱼腥 藻相比更易受低温条件的限制. 总体上本研究结果与上述研究结果一致, 然而略有不同的是, 在温度较高的 夏季巢湖部分湖区也有大量的 $\mathrm{H} 2$ 分布, 其原因仍有待进一步研究. H2 功能群与营养盐浓度呈现负相关, 其 中与 DTN 浓度呈负相关表明其对氮素的非依赖性, 这与其固氮功能具有重要关联; 而与 DTP 的负相关则体 现了其在与微囊藻竞争过程中处于劣势, 微囊藻能够有效抑制鱼腥藻的生长 ${ }^{[24]}$. 水深对功能群组成的贡献 可能主要体现在其对光照和水体混合度的影响, 如更深水深的湖区水下平均可利用光会偏少, 因此具有低 光耐受的功能群 $\mathrm{Y}$ 会在深水处有分布, 而 $\mathrm{H} 2$ 的固氮作用需要更多的能量需求 ${ }^{[25]}$, 其分布的区域可能相对 较浅. $\mathrm{COD}_{\mathrm{Mn}}$ 与 $\mathrm{H} 2 、 \mathrm{M}$ 和 $\mathrm{LM}$ 等的正相关可能是由于藻类的大量生长, 其生物量的增加使得水体 $\mathrm{COD}_{\mathrm{Mn}}$ 增 加, 这与本研究常规监测的结果相一致. 
根据回归结果, 全年最具优势的 $\mathrm{H} 2$ 功能群的显著解释变量有 DTP、COD $\mathrm{Mn} 、 \mathrm{pH}$ 和 DO, 其中贡献较大的 $\mathrm{DTP}(8.5 \%)$ 和 $\mathrm{COD}_{\mathrm{Mn}}(7.6 \%)$ 与 $\mathrm{RDA}$ 结果一致; 全年平均第二优势的 $\mathrm{M}$ 功能群的显著解释变量为水温、 $\mathrm{COD}_{\mathrm{Mn}}$ 和 $\mathrm{DTP}$, 结果与 $\mathrm{RDA}$ 一致, 但是最大解释变量 $\mathrm{pH}(47.9 \%)$ 并未出现在 $\mathrm{RDA}$ 分析结果中, 其原因是 $\mathrm{pH}$ 与功能群 $\mathrm{M}$ 具有自相关特性, 在 RDA 分析中被前向选择笁除. 总体来看, 环境变量对各功能群的解释度都 非常有限, 因此通过功能分类的方式来区分同一个湖泊中环境对种群组成的影响, 虽然较基于物种分类的 方法更有优势, 但仍然有提高的空间, 进一步基于功能特性的物种分类可能是有效提高环境变量对物种组 成影响辨识度的发展方向 ${ }^{[26]}$.

\section{4 结论}

1) 2015 年对巢湖 9 个采样断面所采集的浮游藻类的分类结果显示,巢湖的浮游藻类可以分为 15 个功 能群: C、N、P、MP、S2、X1、X3、Y、F、J、H1、H2、LM、M、W1

2) 巢湖不同时期的藻类功能群存在差异, 其中, H2 在 12 次调查中的优势度均 $\geqslant 0.02$, 成为巢湖的绝对 优势功能群; 巢湖藻类优势功能群不同季节的演替规律为: 1 月 $\mathrm{H} 2+\mathrm{Y}$ 经 2 月 $\mathrm{H} 2+\mathrm{J}, 3$ 月 $\mathrm{H} 2,4$ 月 $\mathrm{H} 2+\mathrm{F}, 5$ 月 $\mathrm{H} 2,6$ 月 $\mathrm{M}, 7$ 月 $\mathrm{M}+\mathrm{H} 2,8$ 、9 月 $\mathrm{M}, 11$ 月 $\mathrm{H} 2+\mathrm{M}$ 转变为 12 月 $\mathrm{H} 2$.

3 ) RDA 分析结果显示, 巢湖藻类功能群分布受水环境因子影响较为明显. 整体上, $\mathrm{COD}_{\mathrm{Mn}}$ 、水深、水温、 DTP 和 DTN 是影响巢湖藻类功能群分布格局的主要因素.

\section{5 参考文献}

[ 1 ] Min WW, Wang PP, LI LJ et al. Relationship between phytoplankton functional groups and environmental factors in the Wei River Basin. Research of Environmental Science, 2015, 28(9): 1397-1406. [闵文武, 王培培, 李丽娟等. 渭河流 域浮游植物功能群与环境因子的关系. 环境科学研究, 2015, 28(9): 1397-1406.]

[ 2 ] Reynolds CS, Huszar V, Kruk C. Towards a functional classification of the freshwater phytoplankton. Journal of Plankton Research, 2002, 24(5): 417-428.

[ 3 ] Jin X, Gruber N, Dunne JP et al. Diagnosing the contribution of phytoplankton functional groups to the production and export of particulate organic carbon, $\mathrm{CaCO}_{3}$, and opal from global nutrient and alkalinity distributions. Global Biogeochemical Cycles, 2006, 20(2):1925-1926.

[ 4 ] Moreno-Ostos E, Cruz-Pizarro L, Basanta A et al. The spatial distribution of different phytoplankton functional groups in a Mediterranean reservoir. Aquatic Ecology, 2008, 42(1) : 115-128.

[ 5 ] Hu R, Lan YQ, Xiao LJ et al. The concepts, classification and application of freshwater phytoplankton functional groups. $J$ Lake Sci, 2015, 27(1): 11-23. DOI:10.18307/2015.0102. [胡韧, 蓝于倩, 肖利娟等. 淡水浮游植物功能群的概 念、划分方法和应用. 湖泊科学, 2015, 27(1): 11-23.]

[ 6 ] Reynolds CS. Phytoplankton assemblages and their periodicity in stratifying lake systems. Holarctic Ecology, 1980, 3(3): 141-159.

[ 7 ] Padisak J, Crossetti LO, Naselli-Flores L. Use and misuse in the application of the phytoplankton functional classification: A critical review with updates. Hydrobiologia, 2009, 621(1): 1-19.

[ 8 ] Chen XJ, Yang J, Du GS et al. Seasonal succession of phytoplankton functional groups and its driving factors in Haizi Reservoir. Water Resources Protection, 2015, 31(6): 122-127. [陈晓江, 杨劼, 杜桂森等. 海子水库浮游植物功能群季 节演替及其驱动因子. 水资源保护, 2015, 31(6): 122-127.]

[ 9 ] Dong J, Li GB, Song LR. Historical changes of phytoplankton functional groups in Lake Fuxian, Lake Erhai and Lake Dianchi since 1960s. J Lake Sci, 2014, 26(5): 735-742. DOI:10.18307/2014.0511. [董静, 李根保, 宋立荣. 抚仙湖, 洱海, 滇池浮游藻类功能群 1960s 以来演变特征. 湖泊科学, 2014, 26(5) : 735-742.]

[10] Li L, Li QH, Jiao SL et al. Spatial and temporal distribution characteristics of phytoplankton functional groups in aha reservoir and their influencing factors. Acta Scientiae Circumstantiae, 2015, 35(11): 3604-3611. [李否, 李秋华, 焦树林等. 阿哈水库浮游植物功能群时空分布特征及其影响因子分析. 环境科学学报, 2015, 35(11): 3604-3611.]

[11] Zhang M, Kong FX. Eutrophication process, spatial and temporal distribution characteristic and control strategy of Chaohu Lake(1984-2013). J Lake Sci, 2015, 27 (5) : 791-798. DOI: 10.18307/2015.0505. [张民, 孔繁翔. 巢湖富营养化的 
历程、空间分布与治理策略(1984-2013 年). 湖泊科学, 2015, 27(5) : 791-798.]

[12] Zhang M, Zhang YC, Yang Z et al. Spatial and seasonal shifts in bloom-forming cyanobacteria in Lake Chaohu: Patterns and driving factors. Phycological Research, 2016, 64: 44-55.

[13] Deng DG, Xie P, Zhou Q et al. Studies on temporal and spatial variations of phytoplankton in Lake Chaohu. Journal of Integrative Plant Biology, 2007, 49: 409-418.

[14] Jiang YJ, He W, Liu WX et al. The seasonal and spatial variations of phytoplankton community and their correlation with environmental factors in a large eutrophic Chinese lake (Lake Chaohu). Ecological Indicators, 2014, 40: 58-67.

[15] Ministry of Environmental Protection of the People's Republic of China, Editorial Board of Water and Wastewater Monitoring and Analysis Methods ed. Water and Wastewater Monitoring and Analysis Methods: 4th edition. Beijing: China Environmental Science Press, 2002. [ 国家环境保护总局《水和废水监测分析方法》编委会. 水和废水监测分析方法: 第 4 版. 北京: 中国环境科学出版社, 2002.]

[16] Zhang M, Yu Y, Yang Z et al. Deterministic diversity changes in freshwater phytoplankton in the Yunnan-Guizhou Plateau lakes in China. Ecological Indicators, 2016, 63: 273-281.

[17] Aksnes DL. Modeling the significance of zooplankton grazing for export production. Limnology and Oceanography, 1993, 38(5): 978-985.

[18] Lampitt RS, Wishner KF, Turley CM et al. Marine snow studies in the Northeast Atlantic Ocean: Distribution, composition and role as a food source for migrating plankton. Marine Biology, 1993, 116(4) : 689-702.

[19] Elena S, Maria C, Alberto B. Geometric shape as a trait to study phytoplankton distributions in aquatic ecosystems. Hydrobiologia, 2013, 701(1) : 99-116.

[20] Reynolds CS. The concept of ecological succession applied to seasonal periodicity of freshwater phytoplankton. Verhandlungen Internationale Vereinigung fur theoretische und angewandte Limnologie, 1988, 23(2) : 683-691.

[21] Jiang X, Wang SH, Zhong LX et al. Seasonal variation characteristics of algae biomass in Chaohu Lake. Environmental Science, 2010, (9) : 2056-2062. [姜霞, 王书航, 钟立香等. 巢湖藻类生物量季节性变化特征. 环境科学, 2010, (9) : 2056-2062.]

[22] Robarts RD, Zohary T. Temperature effects on photosynthetic capacity, and growth rates of bloom-forming cyanobacteria. New Zeal Journal of Marine and Freshwater Research, 1987, 21 : 391-399.

[23] Ohkubo N, Yagi O. Studies on the succession of blue-green algae, Microcystis, Anabaena, Oscillatoria and Phormidium in Lake Kasumigaura. Environmental Technology, 1993, 14: 433-442.

[24] Li Y, Li DH. Competition between toxic Microcystis aeruginosa and nontoxic Microcystis wesenbergii with Anabaena PCC7120. Journal of Applied Phycology, 2012, 24: 69-78.

[25] Paerl HW, Xu H. Controlling cyanobacterial blooms in Hypertrophic Lake Taihu, China: Will nitrogen reductions cause replacement of Non- $\mathrm{N}_{2}$ Fixing by $\mathrm{N}_{2}$ Fixing Taxa? The Public Library of Science ONE, 2014, 9: e113123.

[26] Litchman E, Klausmeier CA, Schofield OM. The role of functional traits and trade-offs in structuring phytoplankton communities: Scaling from cellular to ecosystem level. Ecology Letter, 2007, 10: 1170-1181. 